\title{
Effect of nutriseed pack placement on growth, yield and nutrient uptake of tomato (Lycopersicon esculentum) under drip irrigation
}

\author{
Surabhi Hota ${ }^{1 *}$ and K. Arulmozhiselvan ${ }^{2}$ \\ ${ }^{1}$ Department of Soil Science and Agricultural Chemistry, Indira Gandhi Agriculture University, Raipur-492012 \\ (Chhatisgarh), INDIA \\ Department of Soil Science and Agricultural Chemistry, Tamil Nadu Agricultural University, Coimbatore- \\ 641003 (Tamil Nadu), INDIA \\ ${ }^{*}$ Corresponding author. E- mail: surabhi.hota@gmail.com
}

Received: February 22, 2016; Revised received: August 29, 2016; Accepted: November 11, 2016

\begin{abstract}
A method of crop production of tomato (Lycopersicon esculentum) was attempted in field using Nutriseed Packs with drip irrigation. Nutriseed Pack is a tubular assembly composed of degradable polymer paper encapsulated fertilizer and manure pellet, designed for placing in the root zone soil of seedling at the time of transplanting. Urea/Diammonium phosphate (DAP) as source of $\mathrm{N}$, single superphosphate (SSP)/ DAP as source of $\mathrm{P}$, and muriate of potash (MOP) as source of $\mathrm{K}$ were used. The effect of paper wrap and addition of maida flour as a natural gel to fertilizer pellet was tested. The highest values for growth parameters such as plant height, number of main branches per plant and number of lateral branches per main branch were recorded for Nutriseed Pack with $50 \%$ NP(SSP)K with Wrap + Gel in all stages. Total fruit yield was highest in Nutriseed Pack with 50\%NP(SSP)K with Wrap + Gel $\left(43.1 \mathrm{t} \mathrm{ha}^{-1}\right)$, which was $4.6 \mathrm{t} \mathrm{ha}^{-1}(11.9 \%)$ higher than yield obtained in surface broadcast as $100 \% \mathrm{NP}(\mathrm{SSP}+\mathrm{DAP}) \mathrm{K}(38.5 \mathrm{t}$ ha$\left.{ }^{1}\right)$. The highest uptake of $\mathrm{N}\left(112.4 \mathrm{~kg} \mathrm{ha}^{-1}\right)$ and $\mathrm{P}\left(13.32 \mathrm{~kg} \mathrm{ha}^{-1}\right)$ was recorded for Nutriseed Pack with $50 \% \mathrm{NP}(\mathrm{SSP})$ $\mathrm{K}$ with Wrap + Gel, while the highest $\mathrm{K}$ uptake $\left(105.6 \mathrm{~kg} \mathrm{ha}^{-1}\right)$ was recorded in surface broadcast at $100 \% \mathrm{NP}$ (SSP+DAP)K. The promising effect of placement of Nutriseed Pack has been brought out in the present study as an alternative means of crop production in terms of increase in fertilizer use efficiency upto $50 \%$ in place of surface application of fertilizers.
\end{abstract}

Keywords: NPK, Nutriseed pack, Surface application, Tomato

\section{INTRODUCTION}

Tomato (Lycopersicon esculentum) is an important vegetable crop belonging to the family Solanaceae and one of the most important 'protective foods' because of its special nutritive value. It is one of the most versatile vegetable with wide usage in traditional Indian culinary. For tomato production soil fertility management is crucial for getting maximum yield. For maintaining continual soil productivity, the ratio of nutrient uptake to inputs should be carefully balanced. Continuous supply of macronutrients, mainly nitrogen, phosphorous and potassium and micronutrients are required for tomato production in order to stimulate root development, crop growth, yield and quality. The majority of tomato growers do not produce good quality fruit at high yield levels due to lack of knowledge on improved production technologies including use of proper inorganic and organic fertilizers. Due to the injudicious and imbalanced use of inorganic fertilizers often good yield is not achieved at harvest (Arya and Roy, 2011). Integrated nutrient management usually adopted to enhance yield, however high nutrient use efficiency is not achieved due to surface broadcast of fertilizers.
Alternatively root zone deep placement with slow release principle by Nutriseed Pack placement is highly beneficial as it maintain adequate level of nutrients and provide favorable conditions for achieving high yield of tomato and nutrient use efficiency. Nutriseed Pack Technique has been recently developed in the Department of Soil Science and Agricultural Chemistry, TNAU, Coimbatore. Nutriseed Pack consists of seed at top, manure pellet at middle and fertilizer pellet at bottom. Originally the concept of Nutriseed Pack was developed for the production of field crops which are propagated by seeds like rice and maize. Later, the technique was applied to crops raised by seedlings. Horticultural crops like cauliflower (Aaron, 2011), carnation and marigold (Muthukrishnan and Arulmozhiselvan, 2013) were grown using nutriseed pack which resulted in high yield compared to fertilization by conventional surface broadcast. The present study was carried out to investigate the effect of nutriseed pack placement on growth, yield and nutrient uptake of tomato under drip irrigation.

\section{MATERIALS AND METHODS}

In the present study hybrid tomato 'Bhagyam' was 
raised using nutriseed packs. Since tomato is propagated by seedling, the Nutriseed Packs used in the field experiment contained all components excepting seed. Conceptually, it is still called Nutriseed Pack as the seedling is placed closely just above the Pack. Nutriseed Pack for tomato is composed of manure pellet and encapsulated fertilizer pellet. The manure pellet consists of vermicompost in pellet form. Fertilizer pellet is made up of mixture of NPK fertilizers in pellet form and encapsulated in bio degradable polymer coated paper pouch. The nutrients in fertilizer pellet are equal to the amount as per treatments. Each Nutriseed Pack is assembled by combining these two parts together and wound in newsprint paper as a roll. All these processing are done by human labour with machinery support. At the time of transplanting, the seedlings were planted after implanting the nutriseed packs in horizontal orientation in a small pit. On the top of the pack one tomato seedling was transplanted along with the rooting media. When the seedlings grow, the roots tap the diffusing nutrients from the Nutriseed Pack surface. No top dressing of fertilizers is done. In the field, according to fertilizer quantity as per treatments either one or more (up to 4) fertilizer pellets were used in each Nutriseed Pack, as the fertilizer requirement of tomato was high (200-250-125 N, $\left.\mathrm{P}_{2} \mathrm{O}_{5}, \mathrm{~K}_{2} \mathrm{O} \mathrm{ha}^{-1}\right)$. The field experiment was conducted in TNAU, Coimbatore during 2014-15. The experimental site is geographically situated at $11^{\circ} \mathrm{N}$ latitude and $77^{\circ} \mathrm{E}$ longitude at an altitude of $426.7 \mathrm{~m}$ above MSL. During cropping period, maximum temperature ranged from 29.0 to $34.3{ }^{\circ} \mathrm{C}$ and minimum temperature ranged from 20.8 to $22.8^{\circ} \mathrm{C}$ with rainfall of $5 \mathrm{~mm}$. The crop was raised during the months of December 2014 to March 2015.

The soil of experimental site was calcareous mixed black soil with sandy clay loam texture. Raised beds were laid out having $90 \mathrm{~cm}$ width and $30 \mathrm{~cm}$ furrows with a length of $7 \mathrm{~m}$. Crop was planted at a spacing of $60 \times 35 \mathrm{~cm}$ so as to accommodate the recommended plant population. Eight treatments were replicated three times and randomized according to randomized block design. In each replication, two beds were allotted to one treatment. Laterals of the drip system were made to run in between two rows of crop in a single bed. Urea/ Diammonium phosphate (DAP) as sources of $\mathrm{N}$, single superphosphate (SSP)/ DAP as sources of $\mathrm{P}$, and muriate of potash (MOP) as source of $\mathrm{K}$ were used. Eight treatments were taken including one control and one surface application of $100 \%$ NP( SSP+DAP)K. Other six treatments included Nutriseed Pack placement with two levels (50\% and $100 \%)$ of recommended dose of fertilizers and three types of P sources (SSP alone, DAP alone and 50\% SSP + 50\% DAP) and Maida in the fertilizer pellet as hygroscopic gel additive and newsprint paper as wrap over fertilizer pellet in four treatments. Five plants in each replication were selected at random and tagged for recording observations on growth and yield parameters of different treatments. Five plants selected at random from each plot were uprooted at vegetative, flowering and final harvest stages for estimating dry matter and the nutrient content. For analysis of major nutrients in soil (N, P and $\mathrm{K}$ ) standard procedures such as Alkaline $\mathrm{KMnO}_{4}$ oxidation method for available $\mathrm{N}$ by Subbiah and Asija (1956), Olsen method for available P by Olsen et al. (1954) and $1 \mathrm{~N} \mathrm{NH4OAc} \mathrm{for} \mathrm{available} \mathrm{K}$ by Stanford and English (1949) were followed. For plant N micro kjeldahl diacid digestion by Jackson (1973) , K and $\mathrm{P}$ by triacid digestion, Piper (1966) method were followed. Statistical analysis was done as suggested by Panse and Sukhatme (1967).

\section{RESULTS AND DISCUSSION}

In the field under drip irrigation, evaluation of the performance of treatments revealed the potential capability of Nutriseed Pack placement to support tomato crop up to the final harvest of fruits. The soil had moderate CEC of $20.6 \mathrm{cmol}\left(\mathrm{p}^{+}\right) \mathrm{kg}^{-1}$ soil with 30.2 per cent clay and $5.3 \mathrm{~g} \mathrm{~kg}^{-1}$ organic carbon. Owing to its texture and clay content, the soil had appreciable pore space $(42.73 \%)$, and water holding capacity (39.41\%). Bulk density was optimum $\left(1.35 \mathrm{Mg} \mathrm{m}^{-3}\right)$ and hydraulic conductivity and infiltration rate were moderate. The status of available nutrients was found to be low for $\mathrm{N}$ $\left(254 \mathrm{~kg} \mathrm{ha}^{-1}\right)$ and medium for P $\left(13.4 \mathrm{~kg} \mathrm{ha}^{-1}\right)$ and high for $\mathrm{K}\left(703 \mathrm{~kg} \mathrm{ha}^{-1}\right)$. The effect of Nutriseed Pack placement at $50 \%$ and $100 \%$ NPK levels in comparison with fertilization of $100 \%$ NPK by surface broadcast was registered distinctly in various growth parameters recorded in the study at critical stages of crop growth. While comparing to Nutriseed Pack placement of $50 \%$ and $100 \%$ of fertilizer dose with $100 \%$ of surface application, the effect on plant height, number of main branches, number of lateral branches and number of leaves were significantly different for all the treatments (Table 1). The result recorded for plant height was highest for $50 \%$ NPK as Nutriseed Pack placement as NP(SSP)K with Wrap + Gel in all the critical stages of crop and the result was comparable to that of $100 \%$ NPK by surface application.

With the advancement of growth, number of main branches, number of lateral branches and number of leaves increased greatly showing the appreciable and continued supply of nutrients from the vegetative to fruit setting stage under Nutriseed Pack placement. The result of 50\% NPK application as Nutriseed Pack was comparable to that of $100 \%$ NPK as surface application. Surface application could not achieve the similar effect on number of leaves after vegetative stage probably due to the fact that nutrients applied through surface application were not exactly remained in the root zone in available forms. This conspicuous effect of Nutriseed Pack could be attributed to placement of $\mathrm{N}, \mathrm{P}$ and $\mathrm{K}$ fertilizers in the root zone, which would have synergistically induced crop growth and facilitat- 


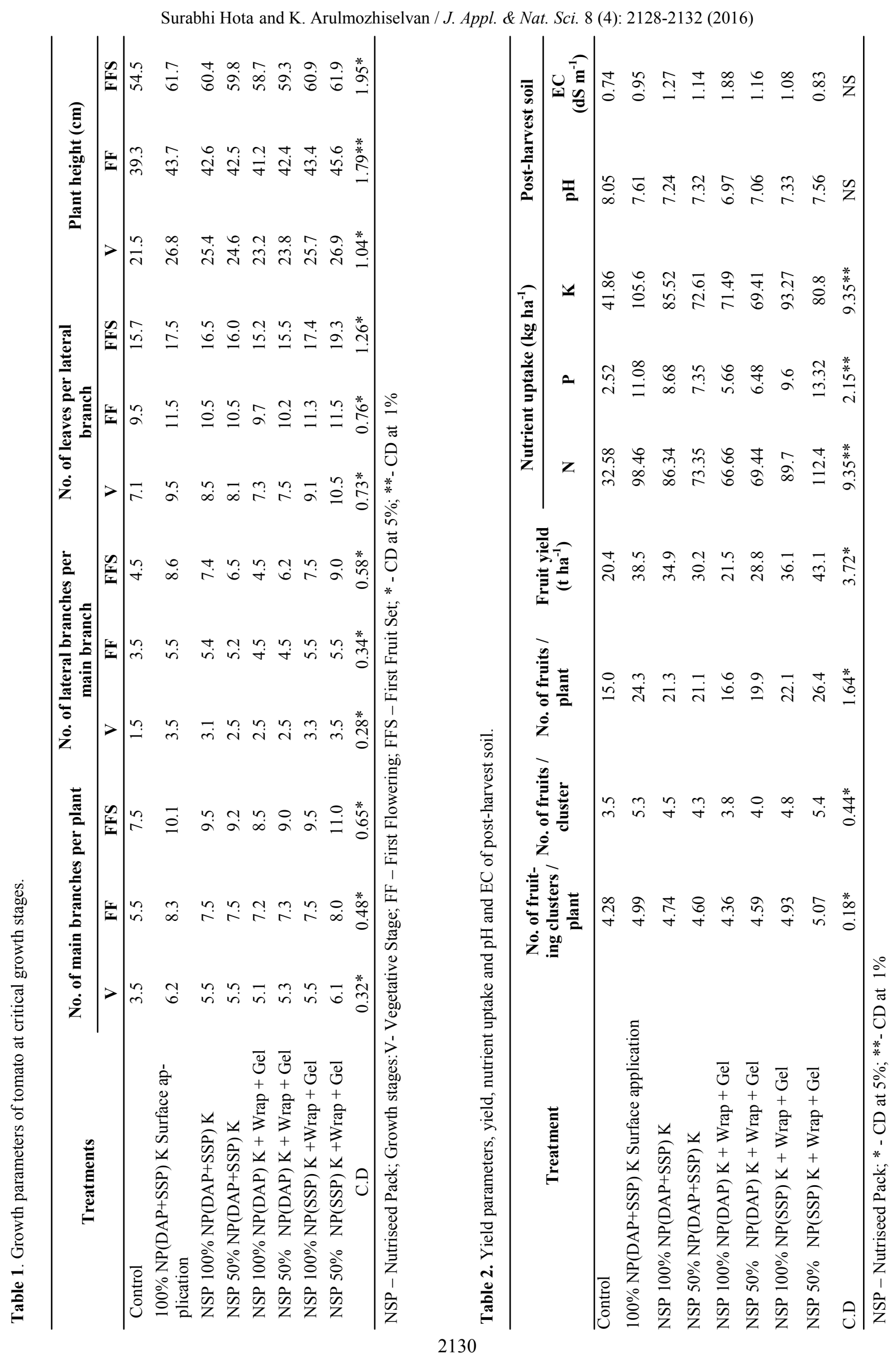


ed increased uptake of major nutrients, continuously tapping nutrients for the growth from the point of placement. Golden et al. (2009) reported that pre-plant incorporated polymer coated urea increased rice grain yield and $\mathrm{N}$ uptake in the direct seeded, delayed flood method compared with urea applied pre-flood at the five-leaf stage. Rehm and Lamb (2009) brought out that placement of fertilizer near the maize seed at the time of sowing increased early growth, $\mathrm{P}$ uptake and yield. Aaron (2011) experimented with Nutriseed Pack treatments and reported higher curd yield of cauliflower for Nutriseed Pack placement when compared to surface broadcast. Kalaiselvi and Arulmozhiselvan (2013) revealed that Nutriseed Pack with different pesticides registered remarkably high grain yield of maize which compared to the conventional surface fertilizer application. The treatments of Nutriseed Pack with 100\% NPK application resulted in less performance when compared to $50 \%$ NPK application. The possible reason might have been the higher concentration of electrolytes released at the root zone due to deep placement as found with higher EC (Table 2) in high level of placement in post-harvest soil. Unfavorable salinity might affect water transport, nutrient absorption and result in reduced growth. The effect of treatments on growth parameters was also reflected in yield parameters and yield (Table 2). The highest value for number of fruiting clusters per plant and number of fruits per cluster was recorded for 50\% NPK Nutriseed Pack placement as NP(SSP)K + Wrap + Gel followed by surface application and $100 \%$ NPK application as NP (SSP) K with Wrap + Gel Nutriseed Pack. Others with $100 \%$ NPK application showed lower value. From the result it was clear that tomato is more responsive to SSP application compared to SSP + DAP and DAP alone. The possible reason may be the calcium and sulfur supplied by SSP and tomato is very much responsive to sulfur and calcium which has been pre-established by many researchers. Total fruit yield per hectare was highest in $50 \%$ NPK Nutriseed Pack as NP(SSP)K with Wrap + Gel which was $11.9 \%$ higher than yield obtained in surface broadcast as $100 \% \mathrm{NPK}$ due to ultimate result of higher number of fruit clusters and fruit per cluster and continuous supply of nutrient at the root zone. The highest uptake (Table 2) of $\mathrm{N}$ and $\mathrm{P}$ was recorded for $50 \%$ NPK Nutriseed Pack as NP (SSP) K with Wrap + $\mathrm{Gel}$, while the highest $\mathrm{K}$ uptake was recorded in surface broadcast at $100 \%$ NPK. Deep placement of Nutriseed Packs altogether might have slowed down volatilization, denitrification and leaching losses and increased the $\mathrm{N}$ availability resulting in higher uptake. Bowen et al. (2004) reported that deep placement of urea could improve the use efficiency of applied $\mathrm{N}$ by keeping most of the urea $\mathrm{N}$ in the soil close to plant roots. Spot application of relatively immobile nutrients like $\mathrm{P}$ would reduce quick dissolution and mobility of soluble $\mathrm{P}$ due to slow diffusion from the applied loca- tion and would enhance $\mathrm{P}$ uptake. Yield benefits to deeper and banded nutrient placement in crops such as corn were reported by Borges and Mallarino (2001). For $\mathrm{K}$ uptake the trend was not similar to $\mathrm{N}$ and $\mathrm{P}$. The possible reason might be the luxury consumption of $\mathrm{K}$ without loss or fixation. It was evident that with $\mathrm{Nu}-$ triseed Pack placement the fertilizer use can be reduced to lower level at $50 \%$ NPK application itself by achieving high yield over 100\% NPK surface application.

\section{Conclusion}

In conclusion, a sensible advantage of using Nutriseed Pack has been realized in the present study. By single, one time spot placement of Nutriseed Pack with $50 \%$ NPK, which has controlled nutrient release mechanism, there was continued nutrient support to the tomato crop till the final harvest, resulting in high fruit yield and cost benefit. By Nutriseed Pack placement, because of increased fertilizer use efficiency, 50\% fertilizer NPK can be saved when compared to $100 \%$ NPK blanket dose prescribed for conventional surface broadcast method of fertilizer application.

\section{REFERENCES}

Aaron, N. (2011). Nutriseed Pack technique for enhancing yield of cauliflower. M.Sc. (Ag.) Thesis, Tamil Nadu Agricultural University, Coimbatore.

Arya, S.K. and Roy, B.K. (2011). Manganese induced changes ingrowth, chlorophyll content and antioxidants activity in seedlings of broad bean (Viciafaba L.). $J$. Environ. Biol., 32: 707-711

Borges, R. and Mallarino, A.P. (2001). Deep banding phosphorus and potassium fertilizers for corn managed with ridge tillage. Soil Sci. Soc. Am. J., 65: 376-384

Bowen, W.T., Diamond, R.B., Singh, U., and Thomson, T.P. (2004). Urea deep placement increases yield and saves nitrogen fertilizer in farmers' fields in Bangladesh. Conservation of soil, water and environment in rice culture, 369-372

Golden, B.R., Slaton, N.A., Norman, R.J., Wilson, C.E., and DeLong, R.E. (2009). Evaluation of polymer-coated urea for direct-seeded, Delayed-Flood Rice Production. Soil Sci. Soc. Am. J., 73: 375-383

Jackson, M.L. (1973). Soil Chemical Analysis. Prentice Hall of India Private Limited, New Delhi.

Kalaiselvi, B. and Arulmozhiselvan, (2013). Nutriseed Pack technique for enhancement of maize yield under drip irrigation. Asian J. Soil Sci., 8 (2): 221-225

Muthukrishnan, R. and Arulmozhiselvan, K. (2013). Response of Nutripellet Pack placement on marigold yield and its components. African J. of Agric. Res., 8(48): 6332-6336

Olsen, S.R., Cole, C.V., Watanabe, F.S. and Dean, L. (1954). Estimation of available phosphorus in soils by extraction with sodium bicarbonate. U.S.D.A. Circ., 939. U.S. Govt. Printing Office, Washington DC.

Panse, U.G. and Sukhatme, P.V. (1967). Statistical methods of agricultural workers, Indian Council of Agricultural Research, New Delhi.

Piper, C.S. (1966). Soil and Plant analysis, Hans Publishers, 
Surabhi Hota and K. Arulmozhiselvan / J. Appl. \& Nat. Sci. 8 (4): 2128-2132 (2016)

Bombay

Rehm, G.W. and Lamb, A. (2009). Corn response to fluid fertilizers placed near the seed at planting. Soil Sci. Soc. Am J., 73: 1427-1434
Stanford, S. and English, L. (1949). Use of flame photometer in rapid soil test for K and Ca. Agron. J., 41: 446-447

Subbiah, B.V. and G.L. Asija. (1956). A rapid procedure for estimation of available nitrogen in soils. Curr. Sci., 25: 259-260 